\title{
Antecedents of Work-Family Conflict and the Moderating Effect of Perceived Organizational Support in China
}

\author{
Do-Hyung Lee ${ }^{1} \&$ Zenglim $^{1}$ \\ ${ }^{1}$ School of Business Administration, Yeungnam University, Gyeongsan, Republic of Korea \\ Correspondence: Do-Hyung Lee, School of Business Administration, Yeungnam University, 280 Daehak-Ro, \\ Gyeongsan, Gyeongbuk 712-749, Republic of Korea. Tel: 82-53-810-2745. E-mail: dh0123@ynu.ac.kr
}

Received: May 30, 2013 Accepted: June 13, 2013 Online Published: September 29, 2013

doi:10.5539/ass.v9n13p28 URL: http://dx.doi.org/10.5539/ass.v9n13p28

\begin{abstract}
This study examines the antecedents of work-family conflict (WFC) and how perceived organizational support (POS) moderates the effects of these antecedents on work-family conflict. For this, the study employs data collected from a sample of 297 primary and secondary school teachers in China and uses various statistical analysis methods, including factor analysis, correlation analysis, reliability statistics, and hierarchical regression. The results indicate that working hours and work stressors were positively related to work-family conflict, whereas leisure time management was negatively related to work-family conflict. Finally, POS had a negative moderating effect on the relationships between leisure attitude, leisure time management and work-family conflict, whereas POS had a positive moderating effect on the relationships between work stressors and work-family conflict.

This study contributes by investigating the antecedents of work-family conflict and the moderating effect of POS on their relationships. The results have important practical implications for Chinese policymakers interested in designing policy initiatives that can help teachers achieve an appropriate balance between their work and life and improve their work-life quality.
\end{abstract}

Keywords: task characteristics, life characteristics, perceived organizational support, work-family conflict

\section{Introduction}

College and high school entrance examination systems are considered as key features of China's education system, which reflects a fiercely competitive selection or elimination system. Therefore, this system has considerable influence on the value orientation of education, school, and teacher management. In this regard, social satisfaction with the education system depends on teachers' commitment to teaching and cultivating students. Therefore education management should focus on both students and teachers. For a better understanding of the realities facing Chinese teachers, the Chinese teacher career pressure and psychological health survey was administered by China's Renmin University (school of public administration \& the human resource research institute) in 2005. Here the questionnaire, released by Sina Education in 2005, was completed by a total of 8,699 teachers from elementary, middle, and high schools and colleges. According to the survey, teacher stress is a core concern in China's education reform efforts. More specifically, Chinese teachers face eight major work stressors, including school entrance examinations and their workload, role responsibility, employment, educational background, job status, professional title, and interpersonal relationships. Since 1993, the Chinese government has made efforts to reform the country's education system and advocated a quality-oriented education system to reduce study burdens on students and improve teachers' work and life conditions. Such efforts have had clearly positive outcomes in terms of student development, but it remains unclear how they have affected teachers through their school's human resource management.

This study surveys teachers in primary and secondary schools to examine their ability to manage work-life balance under the influence of these efforts. In addition, the study examines the moderating effects of POS on the relationships teachers' task characteristic-work-family conflict and life characteristic-work-family conflict. Here the purpose of this research is to guide an appropriate practical solution. Teachers form a crucial group influenced by education reform, and therefore policymakers should design and implement policy initiatives that can facilitate an appropriate balance between teachers' work and life to improve their work-life quality. 


\section{Literature Review and Hypotheses}

\subsection{Task Characteristics}

The task characteristic approach began with the pioneering work of Turner and Lawrence in the mid-1960s. Higgins and Duxbury (1992) found hours worked per week, overtime frequency, and the inflexibility of work schedules to be the major task characteristics. In addition, work demands are either time- or strain-based, whereas work resources include enabling resources and psychological rewards (Voydanoff, 2004). Time-based demands such as long hours at work can reduce the amount of time available for family activities, thereby making it difficult for employees to perform family duties and maintain family relationships. On the other hand, strain-based demands are expected to increase employees' negative emotions, stress, and fatigue. Keith and Schafer (1980) found that the number of hours worked per week is a significant predictor of work-family strain for both women and men. Bohen and Viveros-Long (1981) linked job hours to difficulties in managing personal and family activities. Shamir (1983) reported that working more than nine hours a day can increase conflict between work and non-work facets of life.

Previous empirical research has shown that the availability of flextime can increase employee autonomy or control over work-related matters, which in turn reduces work-family conflict (Thomas \& Ganster, 1995). Long working hours, non-regular vacations, and promotion-related issues can have considerable influence on work-family conflict (Grant-Vallone \& Donaldson, 2001; Liu, 2004). Brough and Micheal (2010) found that alternative work schedules have a positive effect on employees' organizational performance as well as on their work-related attitudes and work-family conflict perceptions and that these outcomes tend to persist over time. Because of assigned duties, the rapid pace of life, and everyday responsibilities/issues, stress arises in various occupations. This stress is considered a prevalent and costly problem in today's workplace.

Certain occupations can be more stressful than others. Many studies have thoroughly examined work-related stress across many occupations. Many factors contribute to workplace stress, including excessive workloads, isolation, extensive working hours, toxic work environments, a lack of autonomy, difficult relationships with coworkers and management, management bullying, harassment, and a lack of opportunities or career motivation. In addition, heavy workloads, time pressure, tight deadlines, and long working hours represent the main cause of management stress (Broadbridge, Swanson \& Taylor, 2000). Based on Kahn et al. (1964)'s seminal work, many western scholars have classified work stressors into role conflict and ambiguity. Rizzo, House and Lirtzman (1970) developed role conflict and ambiguity scales widely used to examine organizational behavior. Peterson et al. (1995) added role overload (one's lack of personal resources needed to fulfill one's commitments, requirements \& obligations) as the third factor in role stress (Peterson et al., 1995). Cox, Griffiths and Rial-Gonzales (2000) indicated that role ambiguity, conflict, and overload are the major forms of role stress in the workplace.

\subsection{Life Characteristics}

Several studies have found there are three dimensions of an individual's life: work, family, and leisure. Kelly and Kelly (1994) tested these three dimensions and found little difference between family and leisure but substantial differences between these two dimensions and work. Leisure, or spare time, is the amount of time spent away from business, work, and domestic chores. Pieper (1963) described leisure as the freedom of the mind and soul fostering the development of culture and contemplation.

Leisure is a fundamental element in the development of culture and may reflect a "mental" or a "spiritual" attitude. Dumazedier (1967) defined leisure as a separate and residual domain of life in which individual choice plays a crucial role. Neulinger's theory of leisure is defined by the psychological state of mind requiring two criteria for leisure: perceived freedom and intrinsic motivation. Schor (1991) defined leisure as the residual time left over from work and Parker (1971) defined it as a derivative of work. Ragheb (1996) provided a deeper understanding of leisure by investigating its subjective meaning, implying that leisure plays a more important part in life than the time left over after work and obligations. Neulinger (1974) defined the leisure attitude as a "particular way of thinking about, feeling about, and acting toward or in regard to leisure". Leisure attitudes vary across individuals (Neulinger, 1976). Triandis (1967) distinguished three components of attitudes: cognitive, affective, and behavioral. Leisure attitudes are defined as a combination of three elements: cognitive, affective, and behavioral components. The cognitive component refers to general knowledge and beliefs about leisure; the affective component, to feelings towards leisure and the degree of liking/disliking some experience; and the behavioral component, to past, present, and intended actions with respect to leisure activities (Ragheb \& Beard, 1982).

The concept of "leisure time" developed in the 19th and 20th centuries. After the industrial revolution, people 
with high standards of living and labor unions fought for better working conditions, and reducing working hours facilitated development. In the context of time, leisure means free or spare time. Here people have opportunities to freely choose what they want to spend their spare time on. Spare time can be seen as free or even leisure time. In other words, it is the opposite of "working hours." Previous studies have examined spare-time management mainly from the perspective of time management (Kuo, 2008). In general, leisure time excludes work, work-like activities, household obligations, and self-preservation activities. Scott (1993) related an individual's time scarcity to leisure, suggesting a negative relationship between demands on free time and stress. Stress is associated not only with increased demands at work but also with decreased amounts of leisure time. Bright (2000) argued that leisure benefits are a holistic structure that supports humans lives, contributing not only to individuals but also to the human kind. Hultsman (1995) indicated that because of work and family responsibilities, "time commitment" (i.e., a lack of time for participation) hinders people from participating in leisure activities.

\subsection{Perceived Organizational Support}

Eisenberger, Huntington, Hutchison and Sowa (1986) were the first to examine POS, defining it as "an employee's perception that the organization values his or her contribution and cares about the employee's well-being." Previous POS research started with the observation that if managers are concerned about employees' commitment to the organization, then the employees is likely to focus on the organization's commitment to them. Eisenberger et al. (1986) found that employees who experience a high level of POS are likely to feel the need to reciprocate favorable organizational treatment with attitudes and behaviors that can benefit their organization and suggested that this notion of commitment provides a basis for their social exchange and application. Therefore, the core concept underlying organizational support theory is POS, which is based on the relationship between employees and their organization.

Rhoades and Eisenberger (2002) provided a meta-analysis of POS and indicated that treatment fairness, supervisor support, and rewards/job conditions are three major forms of favorable treatment received by employees and that they are positively related to POS, which is in turn related to outcomes favored by employees (e.g., increased job satisfaction, positive moods, and reduced stress) and organizations (increased affective commitment, performance \& reduced employee turnover). Overall, employees with a high level of POS are more likely to be committed and willing to engage in extra roles or organizational citizenship behaviors than those employees who perceive that their organization does not value them as highly.

\subsection{Work-Family Conflict}

Early work-life balance programs started by focusing on female employees with young children. Now these programs serve both men and women across all ages and work-life situations. The traditional understanding of the balance between work and life demands refers to work-life conflict (Allen, Herst, Buck \& Sutton, 2000). Work-life balance research is related to stress research. Previous studies have found that job stressors (work pressure \& role ambiguity) can intensify work-life conflict (Allen et al., 2000). In the field of stress research, new questions are being asked about issues such as the effects of work and family stressors on overall well-being, those of job stressors on family life, and those of family stressors on work life.

Work-family conflict first attracted research attention in the late 1980s. Netemeyer, Boles and McMurrian (1996) conceptualized two forms of conflicts between work and family: work-to-family conflict and family-to-work conflict. Hammer, Bauer and Grandey (2003) also defined these two forms, indicating that in work-family conflict, one's work demands interfere with one's ability to carry out one's family responsibilities. Work-family conflict is a source of stress for many individuals and is defined in Greenhaus and Beutell (1985) as a form of inter-role conflict in which work and family roles are incompatible in some respects such that participation in one role is more difficult because of participation in the other role. In addition, work-family conflict arises when time, energy, and behavioral demands of a role in one domain make it difficult to meet those in the other domain (Byron, 2005; Perrewe, Hochwarter \& Kiewitz, 1999). Several studies have noted that work-family conflict is bidirectional and that work domains are more predominant than family ones (Allen et al., 2000; Frone et al., 1997).

\subsection{Relationships between Task Characteristics and Work-Family Conflict}

Working hours are considered as one of the most important task characteristics that can influence and interact with work-family conflict.

According to the OECD (2004)'s report, long working hours increase the perception of the conflict between job and family responsibilities. Therefore, working hours can be considered as one of the most important factors 
influencing work-family conflict. For example, Luk and Shaffer (2005) pointed out that working hours, as a core element of the workplace, can be a stressor impacting work-family conflict. Some studies have found that job stressors increase work-life conflict (Cropanzano, Rupp \& Byrne, 2003; Ogden, 2004). Yavas, Babakus and Karatepe (2008) and Frone, Russell and Cooper (1992) indicated that job stressors are positively related to work-family conflict frequency. Previous empirical research has shown that the availability of flextime can increase employee autonomy or control over work-related matters, which in turn reduces work-family conflict (Thomas \& Ganster, 1995). Long working hours, non-regular vacations, and promotion-related issues can have considerable influence on work-family conflict (Liu, 2004). In this regard, we propose the following hypotheses:

H1 Task characteristics are positively related to work-family conflict

H1 (a) Working hours are positively related to work-family conflict

H1 (b) Work stressor are positively related to work-family conflict

\subsection{Relationships between Life Characteristics and Work-Family Conflict}

Leisure has become increasingly important relative to work and is a major factor influencing individuals' life satisfaction and sense of well-being. Although leisure time may account for only a small portion of most people's daily lives, it has been shown to play a key role in their well-being, providing them with restorative opportunities by allowing them freedom from daily life demands (Juster \& Stafford, 1985). In general, leisure time excludes work, work-like activities, household obligations, and self-preservation activities. In the context of time, leisure means free or spare time. In other words, it is the opposite of "working hours". Bright (2000) suggested that leisure benefits reflect a holistic structure that supports human lives and can contribute not only to individuals but also to the human kind. Several studies have demonstrated that the amount of work time can have positive effects on work-family conflict (Liu, 2004; Luk \& Shaffer, 2005). In fact, it means that leisure time and attitude can negatively relate to work-family conflict.

For example, Scott (1993) related an individual's time scarcity to leisure, suggesting a negative relationship between demands on free time and stress. Stress is associated with increased work-family conflict. Therefore, the direct effect of leisure time management and attitudes on work-family conflict is negative. In this regard, we propose the following hypotheses:

H2 Life characteristics are negatively related to work-family conflict

H2 (a) Leisure attitudes are negatively related to work-family conflict

$\mathrm{H} 2$ (b) Leisure time management is negatively related to work-family conflict

\subsection{Moderating Effects of POS}

POS is an important source of employees' confidence in their ability to cope with role demands (Lazarus, 1991). Stamper and Johlke (2003) reported that POS is negatively related to role stressors, conflict, and ambiguity. Some work-family studies have examined this construct and found support for the main effect of POS on work-family conflict. For example, POS is negatively related to work-family conflict (Grant-vallone \& Ensher, 2001) and Casper et al. (2002) found that POS reduces work-family conflict. In addition, Foley et al. (2005) explored the moderating effect of POS on the relationship between work stressors and work-family conflict and suggested that POS plays a buffering role and thus moderates the positive relationship between work stressors and work-family conflict.

However, while POS generally reduces WFC, a number of studies argue that POS could increase WFC depends on situations (Beehr et al., 2010; Mayo et al., 2007). Furthermore, as POS is provided from organizations to employees, the results could vary depends on how an individual perceives it. Therefore, there could be undesired repercussions depends on the causes of stress, the work, and the characteristics of an individual (Beehr et al., 2010; Mayo et al., 2007). For example, if the cause of WFC is a boss or colleague, their support could be unhelpful to reduce WFC (Cohen \& Wills, 1985). Consequently, we have hypotheses about the moderating effect of POS as follow:

H3 (a) POS moderates the relationship between working hours and work-family conflict

H3 (b) POS moderates the relationship between work stressors and work-family conflict

H4 (a) POS moderates the relationship between leisure attitudes and work-family conflict

H4 (b) POS moderates the relationship between leisure time management and work-family conflict

Figure 1 shows our conceptual model. 


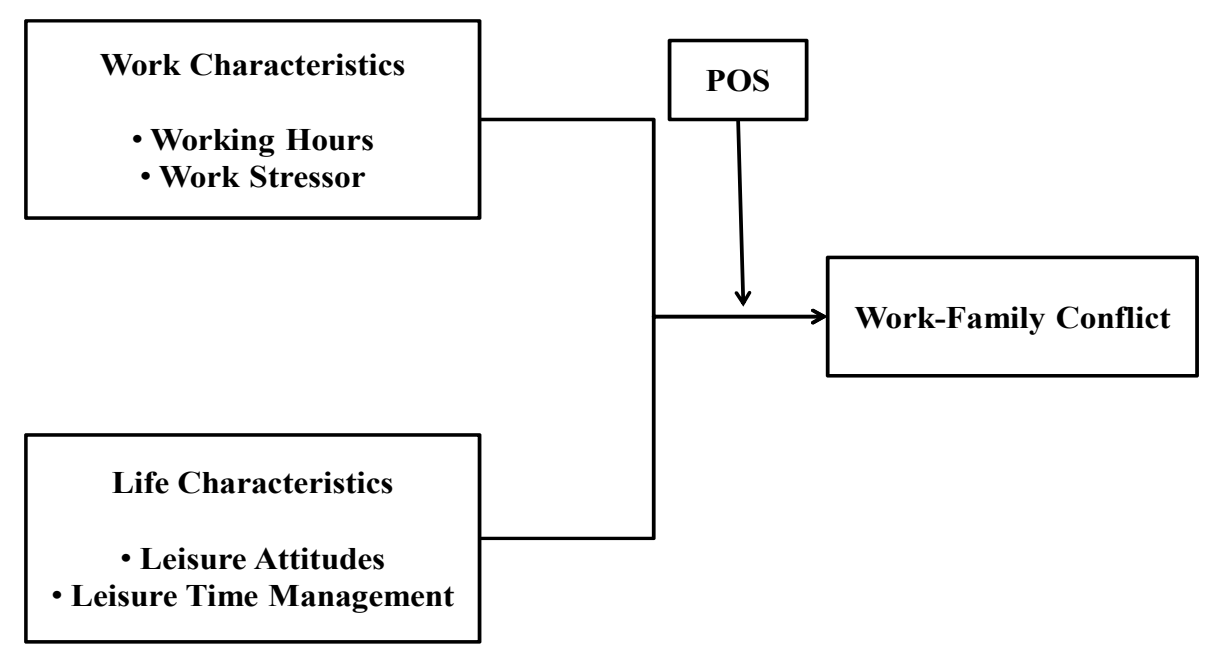

Figure 1. Research model

\section{Method}

\subsection{Sample and Data Collection}

The objective of this study is to examine the factors influencing primary and secondary school teachers' work and life characteristics; investigate the moderating effect of POS; and determine these teachers' current situation in terms of work-life balance management. We analyzed the data by using SPSS 19.0. The main analysis methods were descriptive statistics, factor analysis, correlation analysis, reliability analysis, and regression analysis. We collected the data by administering a survey of 368 teachers from six schools (two primary schools, three middle schools \& one high school). All these schools were public institutions in Hubei Province (central part of China). We distributed the questionnaire to the teachers mainly by sending it directly in their offices. We also collected their responses through the Internet. We distributed a total of 368 questionnaires (300 to offices and 68 through the Internet) and received 297 usable responses (an $81.25 \%$ response rate).

Characteristics of the sample are shown in Table 1. Descriptive statistics are an important tool for examining varying characteristics of stochastic variables. In this study, the demographic variables were age, gender, education, marital status, and the type of school. In terms of age, 102 respondents (34.3\%) were between 25 and 35, and $104(35.0 \%)$ were between 35 and 45. For gender, $97(32.7 \%)$ were male. In terms of the level of education, $222(74.4 \%)$ had a bachelor's degree, and 37 (12.5\%), a master's degree. For marital status, 63 (21.2\%) were single, $224(75.4 \%)$ were married, and only $10(3.4 \%)$ were divorced. Finally, for the type of school, 92 (31\%) were primary school teachers, 183 (61.6\%) were middle school teachers, and $22(7.4 \%)$ were high school teachers. 
Table 1. Characteristics of the sample $(\mathrm{N}=297)$

\begin{tabular}{lll}
\hline Variable & Frequency & Percentage \\
\hline Age & 36 & 12.1 \\
Under 25 & 102 & 34.3 \\
$25-35$ & 104 & 35.0 \\
$35-45$ & 32 & 10.8 \\
$45-50$ & 23 & 7.7 \\
Over 50 & & \\
Gender & 97 & 32.7 \\
Male & 200 & 67.3 \\
Female & & \\
Education & 38 & 12.8 \\
College & 222 & 74.7 \\
Undergraduate & 37 & 12.5 \\
Graduate & & \\
Marital status & 63 & 21.2 \\
Unmarried & 224 & 75.4 \\
Married & 10 & 3.4 \\
Divorced & & \\
Type of school & 92 & 31.0 \\
Primary school & 183 & 61.6 \\
Middle school & 22 & 7.4 \\
High school & &
\end{tabular}

\subsection{Measurement}

Operationalization of constructs on the questionnaire was made using 5-point Likert scales, ranging from 1 (strongly disagree) to 5 (strongly agree). The items used for each scale are shown in Table 3 along with their standardized loadings.

1) Task characteristics

For task characteristics, we considered working hours and work stressors. To measure the amount of time spent at work on a daily basis, we asked the respondents to indicate the number of hours worked each day. We computed working hours through the sum of responses to this item and measured the strength of work stressors by using the job-related tension index scale (Kahn et al., 1964). (Work stressors 6 items, Cronbach's alpha $=.828$ ).

\section{2) Life characteristics}

Life characteristics included two factors: leisure attitudes and leisure time management. We measured leisure attitudes on a 5-point Likert-type scale formed by the original factor structure of the leisure attitude scale (Ragheb and Beard, 1982). We measured leisure time management by using the item "How many hours do you spend on leisure activities on a weekly basis?" (Leisure attitudes management 4 items, Cronbach's alpha $=.894$ ).

\section{3) Perceived Organizational Support (POS)}

We measured the moderating variable, POS, by using a 5-point Likert-type scale. We obtained these nine items from Eisenberger et al. (1986)'s perceived organization support scale (POS 6 items, Cronbach's alpha $=.891$ ).

4) Work-Family Conflict (WFC)

The dependent variable was work-family conflict, which was based on the work-family conflict scale in Netemeyer et al. (1996) (WFC 5 items, Cronbach's alpha $=.882$ ). 


\section{5) Control variables}

We considered age and gender are control variables.

6) Common method bias test

Given that we collected our data from a single informant in each organization at a given point of time, the problem of common method variance could potentially have affected the results. Thus, as Podsakoff et al. (2003) suggest, we ran the Harman's one-factor test in order to assess the risk.

We conducted an explorative factor analysis in which all the continuous variables were inserted. We considered the non-rotated factor solution in order to determine the number of factors necessary to account for the variance among all of the variables. The largest factor that emerged accounted for only 24 percent of the variance. Thus, it could be concluded that common-method-variance bias is not a concern in interpreting the results of this study.

\section{Analysis and Results}

Table 2 presents the means, standard deviations, and correlation coefficients of all the variables. Using the Pearson correlation $\mathrm{r}$, which estimates the degree of linear association, a correlation analyses was conducted. -1.00 to +1.00 is the range for correlation value (Kline, 2005). Table 3 outlines the correlations of all 7 constructs. This analysis shows that there was a moderate correlation between these constructs. The results show that there was high correlation between work stressors and work-family conflict $(\mathrm{r}=.374, \mathrm{p}<0.01)$ while working hours were highly correlated with work-family conflict $(\mathrm{r}=.271, \mathrm{p}<0.01)$. We note that work-family conflict has a negative correlation with leisure time management $(\mathrm{r}=-.146, \mathrm{p}<0.01)$ and $\operatorname{POS}(\mathrm{r}=-.156, \mathrm{p}<0.01)$. This is consistent with prior studies (Casper et al., 2002; Grant-vallone \& Ensher, 2001).

Table 2. Scale means, standard deviations and correlations

\begin{tabular}{llllllllll}
\hline Scale & Mean & S.D & 1 & 2 & 3 & 4 & 5 & 6 & 7 \\
\hline 1. Age & 2.68 & 1.07 & 1 & & & & & & \\
2.WH & 3.22 & 1.15 & -.088 & 1 & & & & & \\
3.WS & 2.78 & 0.75 & -.111 & $.190^{* *}$ & 1 & & & & \\
4.LA & 4.48 & 0.63 & -.023 & .009 & .090 & 1 & & & \\
5.LTM & 3.29 & 1.29 & -.111 & .069 & -.106 & .101 & 1 & & \\
6.POS & 2.85 & 0.86 & -.071 & -.021 & -.089 & -.043 & .079 & 1 & \\
7.WFC & 3.14 & 0.85 & -.042 & $.271^{* *}$ & $.374^{* *}$ & .071 & $-.146^{*}$ & $-.156^{* *}$ & 1 \\
\hline
\end{tabular}

Notes: ${ }^{*} \mathrm{p}<0.05,{ }^{* *} \mathrm{p}<0.01$ (two-tailed)

WH: working hours, WS: work stressors, LA: leisure attitudes, LTM: leisure time management, WFC: work-family conflict

This study analyses reliability of the measurement tool by using Cronbach's alpha. Generally, if Cronbach's alpha value is more than 0.6 , reliability can be viewed as good, and all of the questions can be analysed by summing them up as one measurement (Nunnally, 1967). In our study, reliability of every variable turns out to be relatively high, marking from 0.828 to 0.894 (see Table 3 ). 
Table 3. Final measurement items of constructs

\begin{tabular}{ll}
\hline Construct/items & Factor loadings \\
\hline Work stressors (Cronbach's $a=.828$ ) & \\
I know what my responsibilities are. & 0.694 \\
I have clear planned objectives for my job & 0.765 \\
I know exactly what is expected of me & 0.759 \\
I have to buck a rule or policy in order to carry out an assignment & 0.722 \\
I receive an assignment without adequate resources and material to execute it & 0.727 \\
I receive assignment without the manpower to complete them & 0.664 \\
Leisure attitudes management (Cronbach's $a=.894$ ) & \\
My leisure activities give me pleasure & 0.812 \\
I can be myself during my leisure & 0.909 \\
I feel that leisure is good for me. & 0.873 \\
My leisure activities are refreshing & 0.879 \\
POS (Cronbach's $a=.891$ ) & \\
School management really cares about my well-being & 0.837 \\
School management strongly considers my goals and values & 0.791 \\
School management cares about my opinions & 0.798 \\
School management takes pride in my accomplishments at work & 0.809 \\
School management is willing to extend itself in order to help me perform my job to the & 0.804 \\
best of my ability & \\
Help is available from School management when I have problem & 0.774 \\
Work-family conflict (Cronbach's $a=.884$ ) & \\
The demands of my work interfere with my home and family life & 0.725 \\
The amount of time my job takes up makes it difficult to fulfill family responsibilities & 0.860 \\
Things I want to do at home do not get done because of the demands my job puts on me & 0.861 \\
My job produces strain that makes it difficult to fulfill family duties & 0.802 \\
Due to work related duties, I have to make changes to my plans for family activities & 0.775 \\
\hline & \\
& \\
& \\
&
\end{tabular}

This study examines the antecedents of work-family conflict and how perceived organizational support moderates the effects of these antecedents on work-family conflict. To verify this, it can use hierarchical regression analysis to test the hypothesis. For each analysis, we entered the variables in four distinct steps: the first model examines the control variables; the second adds independent variables; the third adds moderating variables and fourth examine the interaction terms.

In terms of direct effect (H1-H2), Table 4 shows the relationship of the independent variables and work-family conflict. Working hours $(\beta=.219, \mathrm{p}<0.01)$ and work stressor $(\beta=.314, \mathrm{p}<0.01)$ were positively related to work-family conflict. This is concurrent with the views of various previous studies (Liu, 2004; Luk \& Shaffer, 2005; Ogden, 2004). That is to say, the greater working hours and work stressor, the more work-family conflict are encouraged. Thus, H1 (a) and H1 (b) were all supported. By contrast, leisure time management $(\beta=-.131, \mathrm{p}<$ 0.05 ) was negatively related to work-family conflict and the direct effect of leisure attitude on work-family conflict is insignificant $(\beta=.051, \mathrm{p}>0.05)$. These results indicate that if leisure time is increasing, work-family conflict can be reduced. These findings were also concurrent with various previous works (Scott, 1993). Thus, $\mathrm{H} 2$ (a) and $\mathrm{H} 2$ (b) were supported. 
Table 4. Direct effects on work-family conflict (H1-H2)

\begin{tabular}{llll}
\hline Path & Beta & $t$-value & Hypothesis \\
\hline Working hours $\rightarrow$ Work-family conflict $(H 1 a)$ & 0.219 & $4.058^{* *}$ & Support \\
Work stressor $\rightarrow$ Work-family conflict $(H 1 b)$ & 0.314 & $5.763^{* *}$ & Support \\
Leisure attitude $\rightarrow$ Work-family conflict $(H 2 a)$ & 0.051 & 0.952 & Non-support \\
Leisure time $\rightarrow$ Work-family conflict $(H 2 b)$ & -0.131 & $-2.423^{*}$ & Support \\
Age $\rightarrow$ Work-family conflict & 0.003 & 0.049 & \\
Gender $\rightarrow$ Work-family conflict & 0.024 & 0.451 & \\
\hline
\end{tabular}

Note: $* \mathrm{p}<0.05, * * \mathrm{p}<0.01$ (two-tailed tests)

In terms of moderating effects $\mathrm{H} 3$ (a) and $\mathrm{H} 3$ (b), as shown in Table 5, the interaction between working hours and POS was not significant $(\beta=-.253, \mathrm{p}>.05)$ and the interaction between work stressor and POS was significant $(\beta=.456, p<.05)$. It means that POS positively moderates the relationship between work stressors and work-family conflict Therefore, H3 (a) was not supported and H3 (b) was supported.

Hypothesis 4 (a) and 4 (b) proposed a moderating effect of POS the relationship between leisure attitude, leisure time management and work-family conflict. As shown in Table 5, the interaction between leisure attitude and POS was significant $(\beta=-.916, \mathrm{p}<.05)$ and the interaction between leisure time management and POS was also significant $(\beta=-.432, p<.05)$. These results indicate that POS negatively moderates the relationship between leisure attitudes and work-family conflict. Therefore, H4 (a) and H4 (b) were supported.

Table 5. Moderating effect of POS (H3-H4)

\begin{tabular}{lllll}
\hline \multirow{2}{*}{ Variables } & \multicolumn{2}{l}{ work-family conflict } & & \\
& Model 1 & Model 2 & Model 3 & Model 4 \\
\hline Age & -.035 & .003 & -.008 & .010 \\
Gender ${ }^{1}$ & .050 & .024 & .007 & .008 \\
Working Hours & & $.219^{* * *}$ & $.218^{* * *}$ & $.414^{* *}$ \\
Work Stressor & & $.314^{* * *}$ & $.304^{* * *}$ & -.001 \\
Leisure Attitude & & .051 & .048 & $.443^{* *}$ \\
Leisure Time & $-.141^{* *}$ & $-.126^{* *}$ & .181 \\
POS & & $-.111^{* *}$ & $.795^{*}$ \\
WH $\times$ POS & & & -.253 \\
WS $\times$ POS & & & & $.456^{* *}$ \\
LA $\times$ POS & & & & $-.916^{* *}$ \\
LT $\times$ POS & & .201 & .213 &. $.432^{* *}$ \\
$\mathrm{R}^{2}$ & .004 & $12.167^{* * * *}$ & $.012^{* *}$ & $.038^{* *}$ \\
$\Delta \mathrm{R}^{2}$ change & & $11.171^{* * *}$ & $8.692^{* * *}$ \\
$\mathrm{~F}$ & .619 & & & \\
\hline
\end{tabular}

Note: $* \mathrm{p}<0.1,{ }^{* *} \mathrm{p}<0.05,{ }^{* * *} \mathrm{p}<0.01$ (two-tailed tests); standardized coefficients are reported

1. Dummy variable $(0=$ Male, $1=$ Female $)$

In conclusion, based on the data obtained from teachers who work in Chinese primary or secondary schools, the current study found that long working hours and heavy work stress were positively related to work-family conflict and leisure time was negative related to work-family conflict. Results also reveal that POS positively moderated the relationship work stressor-work-family conflict and negatively moderated the relationship leisure attitude-work-family conflict and leisure time management-work-family conflict. 


\section{Discussion}

Teachers form a core part of any education system, and therefore schools and relevant authorities should pay close attention to their work-life quality. In addition, policymakers should consider policy initiatives that can help balance their work and life and thus increase their work-life quality. This study investigates the relationships between teachers' task and life characteristics and work-family conflict. The main empirical findings are as follows.

Firstly, the regression results clearly explain the antecedents (task \& life characteristics) of work-family conflict. In terms of task characteristics, working hours and work stressors were positively related to work-family conflict. For life characteristics, the amount of time spent on leisure activities had a negative effect on work-family conflict.

Secondly, if perceived organizational support (POS) is high, which means employees feel that they are supported by their organization, the effect of work stressors (WS) on work-family conflict (WFC) increase. In other words, the lower POS, the more employees feel less supported by the organization, the effect WS has on WFC decreases. As a result, it is ascertained that the school teachers in China perceive POS between WC and WFC as interference not support. It reflects the characteristic of the Chinese society that the WS affect on WFC increases by perceiving the support from the organization as orders or interference.

Thirdly, the higher POS is, the effects that leisure attitude (LA) or leisure time management (LTM) has on WFC decrease. This means that the effects of LA or LTM on WFC increase when POS is low and supports from organization are perceived low. Therefore, it shows that the school teachers in China believe that POS helps LA or LTM reduce WFC. As a result, it is revealed that the school teachers in China perceive POS differently when it comes to the effect task characteristics and leisure characteristics has on work-family conflict. As for the influences that task characteristics have on WFC, POS is regarded as interference. As for leisure characteristics, POS is perceived as social supports.

A number of implications arise from these results. Firstly, long working hours and heavy work stressors were the main causes of work-family conflict in the work domain. This suggests that although policymakers have generally been successful in reducing burdens imposed on students and in facilitating quality-oriented education, they have not been as successful in terms of burdens facing teachers. Therefore, any education reform should focus not only on students but also on teachers in terms of their well-being.

Secondly, to better balance teachers' work and life, individual teachers and school administrators (or policymakers) should consider the following two practical strategies: First, individual teachers should learn to self-regulate and relieve heavy stress. Second, school administrators should reduce teachers' pressure by appropriately arranging teaching activities for the effective time management of their work and life.

Thirdly, school administrators should have a clear understanding of teachers' needs by age. For example, younger teachers may be more enthusiastic and aspire for compliments and recognition. Therefore, school administrators should provide these teachers with opportunities for further learning and development. One the other hand, middle-aged teachers may focus on achievement. For this reason, school administrators should foster appropriate environments and provide them with substantial support to allow them to advance teaching/research, participate in efforts to reform educational environments, and exchange teaching experiences. For older teachers, school administrators should respect and prioritize them in an appropriate manner.

Fourthly, school administrators should also pay attention to teachers' personal problems and living conditions. For example, teachers' well-being, education of their children, family status, and health require close attention and sufficient support. In terms of leisure time management, the results suggest that if teachers can better manage their spare time to enjoy leisure activities with family members and friends, then they are less likely to face conflicts between their work and family. In other words, leisure plays an essential role in balancing teachers' work and family.

In conclusion, based on the data obtained from teachers who work in Chinese primary or secondary schools, the current study found that long working hours and heavy work stress were positively related to work-family conflict and leisure time was negative related to work-family conflict. Results also reveal that POS positively moderated the relationship work stressor-work-family conflict and negatively moderated the relationship leisure attitude-work-family conflict and leisure time management-work-family conflict.

The present study has a number of limitations. Firstly, we considered teachers only in public schools, excluding those in private institutions. Fieldwork was conducted using a survey of 297 primary and secondary school teachers in China. This was because the management policy for public schools is based on national guidelines, resulting in little difference across public schools. However, because the survey excluded private schools, the results may not fully reflect the current situation in China. We should be careful about generalizing the findings 
to other type of school teacher (such as private school teacher) or teacher in different countries.

Secondly, leisure attitudes were measured as 4 items. Although this study's results show no correlation between leisure attitudes and work-family conflict, future research should adopt other scales to better measure the three major dimensions (cognitive, affective $\&$ behavioral) of leisure attitudes.

\section{References}

Allen, T. D., Herst, D. E. L., Buck, C. S., \& Sutton, M. (2000). Consequences associated with work-to-family conflict: A review and agenda for future research. Journal of Occupational Health Psychology, 5(2), 278-308. http://dx.doi.org/10.1037/1076-8998.5.2.278

Bohen, H. H., \& Viveros, L. (1981). A. Balance jobs and family life. Philadelphia: Temple University Press.

Bright, A. D. (2000). The role of social marketing in leisure and recreation management. Journal of Leisure Research, 32(1), 12-18.

Broadbridge, A., Swanson, V., \& Taylor, C. (2000). Retail change: effects on employees' job demands and home life. The International Review of Retail, Distribution and Consumer Research, 10(4), 417-432. http://dx.doi.org/10.1080/09593960050138967

Brough, P., \& Micheal, P. O. D. (2010). Organizational interventions for balancing work and home demands: An overview. Work \& Stress, 24(3), 280-297. http://dx.doi.org/10.1080/02678373.2010.506808

Byron, K. (2005). A meta-analytic review of work-family conflict and its antecedents. Journal of Vocational Behavior, 67, 169-198. http://dx.doi.org/10.1080/02678373.2010.506808

Casper, W. J., Martin, J. A., Buffardi, L. C., \& Erdwins, C. J. (2002). Work-family conflict, perceived organizational support, and organizational commitment among employed mothers. Journal of Occupational Health Psychology, 7(2), 99-108. http://dx.doi.org/10.1037/1076-8998.7.2.99

Cox, T., Griffiths, A., \& Gonzales, E. R. (2000). Work-related stress. Luxembourg: Office for Official Publications of the European Communities.

Cropanzano, R., Rupp, D. E., \& Byrne, Z. S. (2003). The relationship of emotional exhaustion to work attitudes, job performance, and organizational citizenship behaviors. Journal of Applied Psychology, 88, 160-169. http://dx.doi.org/10.1037/0021-9010.88.1.160

Eisenberger, R., Huntington, R., Hutchison, S., \& Sowa, D. (1986). Perceived organizational support. Journal of Applied Psychology, 71, 500-507. http://dx.doi.org/10.1037/0021-9010.71.3.500

Foley, S., Hang-yue, N., \& Loi, R. (2005). Work role stressors and turnover intentions: A study of professional clergy in Hong Kong. Journal of Human Resource Management, 16(11), 2133-2146. http://dx.doi.org/10.1080/09585190500315141

Frone, M. R., Russell, M., \& Cooper, M. L. (1992). Antecedents and outcomes of work-family conflict: Testing a model of the work-family interface. Journal of Applied Psychology, 77, 65-78. http://dx.doi.org/10.1037/0021-9010.77.1.65

Frone, M. R., Yardley, J. K., \& Markel, K. S. (1997). Developing and testing an integrative model of work-family interface. Journal of Vocational Behavior, 50(2), 145-167. http://dx.doi.org/10.1006/jvbe.1996.1577

Grant-Vallone, E. J., \& Donaldson, S. I. (2001). Consequences of work-family conflict on employee well-being over time. Work \& Stress, 5(3), 214-226. http://dx.doi.org/10.1080/02678370110066544

Grant-Vallone, E. J., \& Ensher, E. A. (2001). An examination of work and personal life conflict, organizational support, and employee health among international expatriates. International Journal of Intercultural Relations, 25(3), 235-259. http://dx.doi.org/10.1016/S0147-1767(01)00003-7

Greenhaus, J. H., \& Beutell, N. J. (1985). Sources of conflict between work and family roles. Academy of Management Review, 10(1), 76-88.

Hammer, L. B., Bauer, T. N. N., \& Grandey, A. A. (2003). Work-family conflict and work-related withdrawal bahaviours. Journal of Business and Psychology, 17(3), 419-436. http://dx.doi.org/10.1023/A:1022820609967

Higgins, C. A., \& Duxbury, L. E. (1992). Work-family Conflict in the Dual-Career Family. Organizational Behavior and Human Decision Processes, 51, 51-75. http://dx.doi.org/10.1016/0749-5978(92)90004-Q

Hultsman, W. (1995). Recognizing patterns of leisure constraints: An extension of the exploration of dimensionality. Journal of Leisure Research, 27(3), 228-244.

Juster, F. T., \& Stafford, F. P. (1985). Time, Goods, and Well-being. Ann Arbor, Michigan: The University of Michigan, Institute for Social Research.

Kahn, R. L., Wolfe, D. M., Quinn, R., Snoek, J. D., \& Rosenthal, R. A. (1964). Organizational stress: Studies in role conflict and ambiguity. New York: Wiley.

Keith, P. M., \& Schafer, R. B. (1980). Role strain and depression in two-job families. Family Relations, 29, 
483-488. http://dx.doi.org/10.2307/584462

Kelly, J., \& Kelly, J. (1994). Multiple dimensions of meaning in the domains of work, family, and leisure. Journal of Leisure Research, 26(3), 250-274.

Kuo, C. T. (2008). A Study of the Leisure Participation, free time management, leisure benefits and training effect of elite athletes in colleges. Unpublished doctoral dissertation, National Taiwan Sport University. Taiwan.

Lazarus, R. S. (1991). Emotion and Adaptation. New York: Oxford University Press.

Liu, K. F. (2004). Hotel Human Resource Management. Taiwan: Yangchih.

Luk, D. M., \& Shaffer, M. A. (2005). Work and family domain stressors and support: Within and cross-domain influences on work-family conflict. Journal of Occupational and Organizational Psychology, 78(4), 489-508. http://dx.doi.org/10.1348/096317905X26741

Netemeyer, R. G., Boles, J. S., \& McMurrian, R. (1996). Development and validation of work-family conflict and family-work conflict scales. Journal of Applied Psychology, 81(4), 400-410. http://dx.doi.org/10.1037/0021-9010.81.4.400

Neulinger, J. (1974). The Psychology of Leisure. Springfield: Thomas.

Neulinger, J. (1976). The Psychology of leisure. Springfield III: Charles C. Thomas.

OECD. (2004). "Clocking in and clocking out: Recent Trends in Working Hours" Policy Brief. OECD observer.

Ogden, J. (2004). Health Psychology (3rd ed.). Open University Press, Berkshire.

Parker, S. (1971). The Future of Work and Leisure. New York: Praeger Publishers.

Perrewe, P. L., Hochwarter, W. A., \& Kiewitz, C. (1999). Value attainment: An explanation for the negative effects of work-family conflict on job and life satisfaction. Journal of Occupational Health Psychology, 4(4), 318-326. http://dx.doi.org/10.1037/1076-8998.4.4.318

Peterson et al. (1995). Role Conflict, Ambiguity, and Overload: A 21-Nation Study. Academy of Management Journal, 38, 429-452. http://dx.doi.org/10.2307/256687

Ragheb, M. G. (1996). The search for meaning leisure pursuits: review, conceptualization and a need for a psychometric development. Leisure Studies, 15(4), 245-258. http://dx.doi.org/10.1080/026143696375549

Ragheb, M., \& Beard, J. (1982). Measuring Leisure Attitude. Journal of Leisure Research, 14(2), 155-167.

Rizzo, J. R., House, R. J., \& Lirtzman, S. I. (1970). Role conflict and ambiguity in complex organizations. Administrative Science Qurterly, 15, 150-163. http://dx.doi.org/10.2307/2391486

Schor, J. (1991). The Overworked American: The Unexpected Decline of Leisure. United States of American: Harper \& Collins Publishers.

Scott, D. (1993). Time scarcity and its implications for leisure behavior and leisure delivery. Journal of Park and Recreation Administration, 11(3), 51-60.

Shamir, B. (1983). Some antecedents of work-nonwork conflict. Journal of Vocational Behavior, 23(1), 98-111. http://dx.doi.org/10.1016/0001-8791(83)90062-3

Stamper, C. L., \& Johlke, M. C. (2003). The impact of perceived organizational support on the relationship between boundary spanner role stress and work outcomes. Journal of Management, 29, 569-588.

Thomas, L. T., \& Ganster, D. C. (1995). Impact of family-supportive work variables on work-family conflict and strain: A control perspective. Journal of Applied Psychology, 80, 6-15. http://dx.doi.org/10.1037/0021-9010.80.1.6

Triandis, H. C. (1967). Toward an analysis of the components of interpersonal attitudes. In Carolyn \& Sherif (Eds.), Attitude, Ego-Involvement and Change (pp. 227-270).

Voydanoff, P. (2004). Implication of Work and Community Demands and Resources for Work-to-Family Conflict and Facilitation. Journal of Occupational Health Psychology, 9(4), 275-285. http://dx.doi.org/10.1037/1076-8998.9.4.275

Yavas, U., Babakus, E., \& Karatepe, O. M. (2008). Attitudinal and behavioral consequences of work-family conflict and family-work conflict: Does gender matter? International Journal of Service Industry Management, 19(1), 7-31. http://dx.doi.org/10.1108/09564230810855699

\section{Copyrights}

Copyright for this article is retained by the author(s), with first publication rights granted to the journal.

This is an open-access article distributed under the terms and conditions of the Creative Commons Attribution license (http://creativecommons.org/licenses/by/3.0/). 